\title{
Meaning and Religion: Exploring Mutual Implications
}

\author{
LLUIS OVIEDO \\ Pontifical University Antonianum \\ loviedo@antonianum.eu \\ ORCID: 0000-0001-8189-3311
}

\begin{abstract}
Meaning" and "religion" appear as deeply interlinked concepts in modern thought. Theology has often discovered religious faith as a "source of meaning" and philosophy of religion has tried to better describe that link to show how religion provides meaning, or is built through structures of meaning, or is a form of "meaning-construction". Cognitive approach may add new perspectives to better explain this implication. Recent attempts combine scientific methods and philosophical analysis to show how meaning is built and works, and how religion provides a specific sort of meaning, distinct from other forms in which meaning displays itself. Describing religion in terms of "meaning building" helps to better understand its specific role and function in the human mind, and offers a more balanced view on its cognitive dimensions. Different attempts to connect religion and meaning are reviewed in this paper in order to offer a complement to the new scientific study of religion.
\end{abstract}

Keywords: purpose; hermeneutics; systems theory; religious coping; information theory.

Meaning used to belong to the field of the so called "normative disciplines", like philosophy, ethics, theology, and hermeneutics, but this is not an exclusive right. Recently, several scholars have tried a more scientific 
approach to the issue of "meaning", possibly Roy Baumeister did open that path (1991); but many others have followed the same track, often resorting to empirical and experimental methods (Flanagan 2008; Park 2010; Hicks and Routledge 2013; Routledge 2018). However, such a program appears as problematic to many.

Back to the religious experience, the cognitive study of religion can find difficult to render a scientific view of the links between religion and meaning, a connection perceived nevertheless as natural in other intellectual settings. Traditionally it has been claimed that religion confers meaning or purpose to the life of most people; surely it constitutes the main source of meaning for the great majority of world's population. It is worthy to ask whether a more specific cognitive-scientific approach might offer a valid account of that connection, and of the mutual implications seemingly characteristic of such experiences.

A first step consists in clarifying how meaning might be related to religion. As "meaning" can be understood in different ways and is used in different contexts, it becomes necessary to distinguish and to clarify the ground. At least three ways appear as relevant: the existential one, bound to the expression "meaning in life"; the hermeneutic one, related to the understanding of texts and historical events; and the semantic one, or the technical "meaning of words". This paper focuses mostly on the first approach.

Assuming seriously the issue of "meaning" to explain religion has consequences, especially when considering the standard models in Cognitive Science of Religion (CSR). This study will describe how meaning and religion may be related in a more "scientific way", resorting to systems theory and other theoretical tools, and prospecting a research program that aims at providing data and evidence about this alternative approach. So it presents a complement to the current proposals in the new scientific study of religion.

The article will introduce first to the polysemic nature of the idea of 'meaning', trying to better clarify its range and applications, all related to religion. Then, it intends to make the case for assuming that abstract category as a clue for the new scientific study of religion. A further step will 
apply three important models or theoretical frameworks that could assist in that program; to land finally with proposing possible empirical developments and applications to render more scientifically acceptable such a proposal.

\section{How many meanings? How much religion?}

The word "meaning" is related at least to three distinct realms; in all three meaning points to a transformation of an experience, event, text or sign into a content with relevant information for somebody, or for a social group. These realms are:

- The anthropological-psychological realm, where it is currently described as "meaning in life", and opposite to "meaningless life". In this realm, religion has played traditionally, at least since the transcendental and existentialist wave in XX century, a central role, as an instance providing "meaning" or "purpose". Beyond the theological inflections of this issue, the cognitive approach has suggested that religious beliefs are able to set goals, to fix models and to exercise a regulatory role on the life of more committed people (McCullough and Willoughby 2009; Newton and McIntosh 2013). The issue of the central unit in Fodor's analysis of the mind, suggests that religion may play a similar role (Fodor 1983). These views may put "cognitive flesh" into the traditional view of religion as provider of meaning, that now may be translated into playing a leading instance in many human affairs or setting targets and the most important and ultimate objectives.

- The hermeneutic and historic realm, in which meaning regards the content or information of a text, a work of art, or an historical event. In this case meaning relates to aspects relevant to an agent, and is similar to "relevance", or the interest points outstanding among many others deemed less central. Other way to express the same idea is meaning as the way that reveals the so called "salience" in a process or code. Religion plays a role which can be identified in several ways. For instance, George Steiner aesthetic approach suggests that religion becomes a transcending instance that assist in raising the 
meaning of art works, as otherwise the steady displacement of their reference renders it hard to fix (Steiner 1989). A different approach is represented by the German sociologist Niklas Luhmann, for whom the meaning of many events requires a kind of "system" able to hide the constantly excluded dimensions in the process of communication and apprehension of content (Luhmann 2000). However, meaning in this case is a dimension involved in the access to religious texts and experiences, and so, a certain "hermeneutic circle" appears as unavoidable, as long as procedures of interpretation allow for a perception of the right (as opposite to wrong) religious meaning; and, at the same time, this same religious experience allows for a more focused ability to grasp the meaning in such events or texts.

- The third dimension of meaning is more concrete or minimal and regards the semantic question of how words or language can express content or be intentional. The philosophical discussion, lead by Paul Horwich (1998), and the anthropology studies at the end of the nineties about how the meaning of words and symbols is fixed, learned and transmitted, is very informative. These readings manifest the difficulties met when trying to build a good model able to keep the link between symbol or sign and content. Connectionism seemed a good option in former decades, but perhaps not the best in our days. The remaining question appears as linked to the issue of consciousness, intentionality, and the discussion on reductionism and its limits. Once more, religious faith is someway entrenched in the discussion, as a more substantive concept of human nature seems to be required if the issue of meaning will be better assessed. The human being as able to confer meaning, use symbols, and communicate in a much broader spectrum, is probably linked to a certain anthropology able to recognize such mental dimensions, a step closer to the religious understanding, or at least a condition for any substantial religious experience. It appears that a link correlates or establishes an affinity between both dimensions: the one dealing with the possibility of perceiving meaning from linguistic signs, and the one rendering conceivable the religious dimension inside a conscious subject. Indeed, as has been often observed, language, 
scripture and words as signs play a big role in the configuration of many religious expressions; or in other terms, the structure of language, and especially written language, has something numinous per se that invites to a religious or transcendental view; or perhaps in the other way: religious expression finds in language a "sacred expression", a kind of miracle, a magic power rendering language able to accomplish much more than these poor signs or voices could induce one to expect.

In all cases, meaning is deeply entrenched in the social fabric of human existence, hardly can be isolated or perceived as something purely personal (even in the first case and following more existentialist tendencies) and related to culture as the matrix of every form of meaning. Meaning results from an insertion into a framework where symbols claim content, information is available, and the individual negotiates with collectives or, rather, is connected into a social network, as a condition to render it available, and subject to transformation and redefinition. In such conditions, religion and meaning share a deep structure beyond the limits of sheer mental states, and claims for a more collective disposition or form of processing. Other aspects such as emotions, history and ontogenetic development, are closely involved, as meaning is very sensitive to these variables and factors, but these points are beyond the scope of the present research, which aims to highlight the complexity and the many connections linking religion and meaning.

Trying to abound in this already complex panorama, it may be instructive to describe in contrasting ways different approaches to meaning and its functions. The following are just examples that may help to better perceive the described complexity:

- Meaning as information processing (Neuman 2006); and as an analogic process (Shore 1996).

- Meaning as hidden, better ignored, restrained; and as showing or revealed, aware of purpose, explicit (Luhmann 2000; Eagleton 2007, 15).

- Meaning as difference, distinction and displacement; or meaning as integration, whole, and totality, as summing up (Baumeister 1991). 
- Meaning as referred to values or moral ideal on human flourishing (eudaimonics, Flanagan 2008); or referred to experiences, memories and expectations.

- Meaning as an issue of limits and exceptional tragedy; or meaning as a quotidian existential issue (Park 2010).

\section{A risky procedure: meaning as a clue for the study of religion}

To introduce the idea of meaning in the scientific study of religion constitutes a hazardous move and certainly something not easy to integrate into what can be called "the new scientific study of religion", involving evolutionary biology, neurology and cognitive sciences. While the standard approach takes religion as a kind of "dependent variable", the alternative restores its original higher status; while the first deals with an epiphenomenon, or at most with an adaptive mechanism, the second relies on its distinct human status; while current scientific views try to reconstruct religion as a result of external and contingent pressures, the new one provides an internal root to religious behavior, and stresses its peculiar and unmistakable quality. Nevertheless, some developments from Cognitive Science of Religion (CSR) could be connected with the focus on meaning. For instance, several views in that new approach point towards a more top-down causation in the way religion is conceived and works, against other views pointing to a rather bottom-up causation, where adaptive pressures play the bigger role. But even in that case, the evolutionist model could clearly apply when assuming religion as a way of meaning construction, and so a way to deal with failures or cope with distress.

What is the issue at stake? Well, perhaps it depends upon how much a scientific approach can take into account the suggested dimension and its functions, or to acknowledge that in some cases human nature transcends the sheer biological and cognitive constraints (in the narrow computational sense) and points to something more, if life is worthy to be lived, and is not reduced to its biological constituents. However, this is not the only way to 
address the question from a scientific view, since such self-transcending capacity could be easily integrated into a cognitive framework in a fruitful way.

Many people say that they would like to die, rather than live a void meaningless life, a hard-to-find behavior among other animals. To take into account this "new variable" implies some revision or broadening of the available model built by bio-cognitivists in the last years, and where religion could be reduced to other basic elements or activities, broadly shared by other sentient beings. Nevertheless, a different model could keep track of the cognitive structures and the biological constrains, but making place at the same time for mechanisms of meaning construction and self-transcending abilities.

One of the first points to review is to which extent a reductive and even eliminationist program can be pursued into an end, brought to its last consequences, and whether it can successfully provide a convincing account of religious behavior. When this program is pursued, the question rising at the end is: Is it all what religion is about, or is there something missing? To recall that the issue of meaning can - at least - play a role in the religious mind implies that the reductivist program is incomplete, even if it may provide useful insights and information.

Several critics have pointed to the weaknesses of the naturalist and reductivist program as the main theoretical framework in scientific development (De Caro and Macarthur 2004; Gasser 2007; Horst 2007). Some philosophers of science clearly show the limits of such a program, especially when it is assumed in the field of cognitive science, and recall the necessary methodological pluralism guiding different scientific fields, without trying to reduce one to more basic disciplines, or dealing with smaller dimensions (Horst 2016). From this point of view, a program that reduces religious conscious phenomena to its neurological and biological substrate is incomplete, since it neglects the emergence of higher and more complex traits, of new properties that lead to the conscious mind.

Attribution of meaning is a conscious predicament, even if it may be motivated, nourished or disturbed by unconscious dynamics. If such element 
has to be taken into account, then a distinct kind of scientific approach to religion is required, more in line with cultural settings, emotional components, personal and shared memories and other factors involved in the conscious mind, and in the process of attribution of meaning.

\section{Is it available any scientific approach to meaning and religion?}

It is tempting to conclude that the issue of meaning is too abstract or has too many normative sides to become a subject of scientific inquiry; better to leave it to philosophers, humanist psychologists, and theologians. Science will hardly become a "source of meaning", but it can help to highlight the mechanisms and processes underpinning the formation and perception of meaning.

It is difficult to deal in a short paper with a so broad and complex issue, involving many aspects, from semantics and communication sciences, to anthropological and philosophical issues. The present attempt will just offer an outline of possible ways to better describe the dynamics linking religion and meaning. At least the following theoretical frameworks deserve to be pursued: the theory of systems, where meaning and religion find a particular place; the cognitive science trying to recognize and fix processes of meaning formation; and the theory of social cognition, as meaning plays in the interface between personal perception and social norm.

It is necessary to remind about other attempts and programs that have tried to link religion and meaning, in settings like social sciences and anthropology. The names that come to mind are: Clifford Geertz and his definition of religion as a system of symbols inside a hermeneutic understanding of culture (Geertz 1973); Peter L. Berger and his proposal linking meaning and religion as a mature development in his sociology (Berger 1980); or the more recent developments by Robert Bellah trying to figure out the origins of religion related to ritual and symbolic practices (Bellah 2011). All this can be received as building blocks for a theoretical construction. New elements can be added to enrich the list of available models. 


\subsection{Religion and residual meaning}

Meaning in Luhmann's version of systems theory is a very broad concept that describes the functioning of psychic and social systems. In few words, it designates the ability to distinguish between possibility and actuality, between what is chosen and what is kept for future choices. It is closely related to decision and communication, as this last has to do with the choice between what message to send, and what not - yet - to transmit. Meaning operates ever as a selection, a process excluding and deferring further possibilities, and in this way everything becomes contingent, may or may not be selected. Through meaning, the complexity of the world is at the same time kept and reduced. Luhmann clearly states that meaning is a performance or operating form of only psychic and social systems, not of machines or of other living systems; it is a characteristic of the distinct way the former special systems behave.

Meaning operates at three different levels or dimensions: objective, social and temporal. The first case selects between an object or another of attention, between a topic or another of communication; it is a way to reduce complexity. In the social dimension, meaning is built through the distinction between me and the other, between communication partners, and implies a double contingency; meaning should take into account in its operation the perspective of the second person, who operates his/her own selections, and so claims for some "coordination". The temporal dimension of meaning distinguishes between past and future; it identifies the processes duration. Systems operating with meaning are those able to distinguish and to integrate all these three dimensions, or, in other words, to operate into this complex pattern: selections of things or themes; selection of perspectives between the own and other's view; and selection of time and process.

It is important to keep in mind that meaning as a general operation in those systems is specified by every differentiated social system, giving place to distinct kinds of selection: economy, science, politics and affective relations operate through their own way to generate meaning, or to decide between possibilities according to their own code. In this sense, religion is 
not the only system dealing through or with meaning; there is an "economic meaning" to be perceived in several events; the "scientific meaning" present in many aspects of the real world is at hand; or it can be stated that this or that social process or decision "makes sense" from a political point of view. All this recalls that every social system is constituted as a set of communications inside a code or "generalized symbolic medium". The issue at stake is what is the specific modus operandi of religion concerning meaning that is its peculiar way to deal with meaning.

Luhmann's theoretical development knows different proposals as an answer to the last question. In the first place, religious meaning has to do with the management of the difference between transcendence and immanence, or between worldly reality and what may be perceived beyond that. The way religion provides or produces meaning has to do with a communicative selection placing an event or process into that distinction, able to "transcend" the immediate order of things. When the connection with this alternative order of reality is achieved, then we have "religious meaning" (Luhmann 1977). A second way points to the ability of religious communication to overcome or to hide the paradoxes generated by the self-referential process of all psychic and social systems. Religious meaning in this case has to do with the aptitude of that system to manage such paradoxes, which otherwise could become destructive (Luhmann 1985). In the most mature expression, religious meaning has to do with the possibility to connect the indeterminate and the determinate, or to manage the difference between what can be observed and what cannot be observed (Luhmann 2000).

Which are the practical lessons to be learned from this very abstract presentation of the issue of meaning? Luhmann is convinced that meaning in religion has not to do with its "modern crisis", with "its decline" requiring a new provision, or its overcoming through new certainty and adequate answers; it should neither be thought of as a human need that religion fills (Luhmann 2000, 35). All this reveals rather a philosophical view, centered on anthropological priorities and a dated worldview; all this does not help to better understand how religion process meaning. Its particular performance points rather to the possibility to communicate the part of reality left aside, 
or displaced through normal communication in other social systems. It is not clear whether such a "function" becomes unavoidable, both at the individual and at the social level. Luhmann has once stated that at the individual level such function could be avoidable, but not at the social (Luhmann 1989, 349). By the other hand, his most recent view (Luhmann 2000) seems to imply that once a society has reduced contingency to a point, and manages to deal with the most important issues, this residual or displaced area may even be dismissed or forgotten, as rather irrelevant, or not worthy to spend too many energies on it. In any case, it seems that communicating on this displaced or excluded sides may be quite important and "makes sense"; or in other words, the unavailability of such a system or meaning dimension could leave a kind of "black spot" and introduce some instability.

After this brief review, it is useful to show that Luhmann has along his different approaches to the study of religion kept some common ground, despite his evident evolution: religion has to do with what is excluded or not determined through the normal functioning of other systems dealing with meaning. It is not to speak about an "ultimate meaning", but rather with a "residual" one.

Trying to translate all this into more cognitive terms, and in the inevitable interface between individual mind and collective - social - cognition, religion has to do with meaning as a way to cope with aspects or areas left out of consideration, as cognition is ever focused, and cannot deal with very broad or an all-encompassing view. Rather than being a by-product of other cognitive processes (agency, mind reading...), in the way that the ongoing view declares (Boyer 2001, Atran 2002) it may be viewed as a different kind of by-product from other cognitive realms, but in a more ambitious fashion: every cognitive act reduces and focuses, leaving aside what is not assumed or observed. This amount of "left behind" issues, or not treated by the usual processes, becomes the scope and the reason for the rise of a new cognitive ability: the religious one.

In some way, religious performance may be considered a derivative or secondary, in reference to other primary aspects of cognition related to survival and reproduction, but it becomes nevertheless necessary and 
central, as it allows for a better cognitive re-mapping or re-distribution and organization of the mind. Even if it may arise secondarily, once in place, this new arrived cognitive faculty allows for a better arrangement of the human mind. The sense of the proposed hypothesis is quiet intuitive: once you can count with such a faculty, dealing with residual or unmanaged meaning, you can operate better and more freely in the other faculties or cognitive domains, as they do not need to care about that left over aspect; in some sense, they become "discharged" and freed to better focus on their own realms, without caring for the displaced or deferred issues; it leaves the other "instance" to care about it.

\subsection{Religious meaning as big selector}

A different approach may be tried when the issue of meaning is placed more into a theory reflecting on the role of consciousness and on decision making.

Merlin Donald is one of the authors who has better approached the study of consciousness as an instance of "cognitive governance". From his point of view, after taking into account cases of cognitive impairment and neurologic studies, consciousness plays a central role beyond the minimalist characterizations from alternative views. In his own words:

[Consciousness] is about building and sustaining models of reality, constructing meaning, and exerting autonomous intermediate-term control over one's thought process, even without the extra clarity afforded by having the explicit consensual systems of language (Donald 2001, 75).

Other central issue in his theoretical development points to the role played by symbol in the evolution of the human mind and its conscious governance. Being that religion is a traditional provider of strong and broadly shared symbols, it is plausible to deduce that religious beliefs play a central role in the conscious elaboration of meaning.

An alternative approach is offered by the economist Douglass North (2005). In his view cognition is an exercise in which persons "structure their environment in order to reduce uncertainty in human interaction" (North 
2005 , 6). Institutions play a big role in helping to cope with uncertainty and to provide order. Meaning may be seen in this context helping to this performance of reduction of uncertainty. It can be read as a different version of the principle of "contingency management" (Luhmann). Operating under conditions of uncertainty facilitates innovation and flexibility, as it allows for new adaptations and better performances, but it requires at the same time "buffers" and systems to keep in check its levels; and there religious beliefs can play a clear role.

In a converging fashion, empirical studies suggest in which way some kinds of religious beliefs - not all of them - may work as devices providing self-control, or "cognitive governance”. Michael E. McCullough and Brian L. B. Willoughby have reviewed many studies on "Religion, Self-regulation, and Self-Control” (McCullough and Willoughby 2009), showing the mechanisms at work when these beliefs manage to regulate and keep in check human behavior. In the view of the authors:

Religion influences self-regulation by influencing people goals", and this may happen through the following ways:

a) Religion influences goal selection

b) Religion increases the importance of some goals by sanctifying them

c) Religion reduces conflict among goals

d) Religion influences how goals are internalized (71).

Further relevant steps in this same direction include "self-monitoring" and "self-regulatory strength". What seems to reveal all this research is that religion plays a big role in a sector of people, contributing to select what they deem as more convenient. In the words of the authors:

[...] intrinsic religiousness may cause people's goals to become saturated with religious meaning" (78); "Religion may influence the goals that people select, influence the importance associated with those goals, reduce conflict among those goals, and influence the process by which religious teachings are converted into personally meaningful principles (80). 
The suggestion is that "religious meaning" becomes a kind of enforcer for other dimensions or domains of human behavior. Delivering "meaning”, religion is likely to elicit powerful selections, and to strengthen those with an authoritative voice, able to preserve them from the influence of other forces at work.

This theory deserves some comments. In the first place, religious meaning is not a kind of "universal pattern", but a variable that registers different levels of intensity and influence among a broad sample of population. As religion becomes a kind of "powerful selector" it appears as a possible consequence that other providers of "strong meaning" could perform a similar job as the one attributed to religion. Take the case of persons in love. When the loving experience becomes very strong, it works as a powerful selector too, influencing "goal selection", "sanctifying some goals", and the like. It may even take the place of religious feelings and beliefs, as we know from the romantic literature. It may be rather exceptional or at least a transitory state, but nevertheless it reveals a similar dynamic: for the person in love "meaning" points to all what helps to approach the beloved other; meaningless is what keeps away from him/her.

In connection with the proposed insights, Newton and McIntosh (2013) provide another elaborated model about the uniqueness of religious meaning. They point to four factors: comprehensiveness, or the ability religion has to connect different features and events and to integrate them in a whole; sacredness or the recognition of a higher worth and significance or a sense of future fullness; particular religious beliefs, or distinctive and showing a divine plan for an apparently chaotic and unpredictable reality; and social components, or the network that supports and enforces beliefs and their meaning functions.

When we deal with religion in a strong sense, it seems that often this may be considered as what sets the goals and "changes the agenda" of aspirations and desires. Nevertheless the issue needs to be stated better, as meaning has to do with highest aims or purpose, and religion can or cannot be put in this perspective, as very often religious experience is rather "collateral", "derived" or "secondary" and just deals with, or builds 
a specific kind of "meaning", the religious one, no higher, no lower than other sources or forms of meaning, but just the "spiritual" or the one "linked with transcendence”, as Luhmann put it.

The issue at stake is the centrality of religion in our make-up. This seems to be the right way to understand religion, in its own traditions: as something absolute. Robert Spaemann made a similar point years ago: we cannot understand religion until we do not consider it at the center or the top of our life, and not as a dependent variable (Spaemann 1994). However, this point reflects a radical view of religion; while very often it becomes rather a kind of "variable" in the life of people, from more to less intensity, and so it becomes hard to establish as an all or nothing strategy. It is apparent that the formation of habits, in the sense pointed by Norbert Elias and Pierre Bourdieu - the concept of habitus - plays a big role in all this process of meaning construction, in the religious field as well (Elias 1994; Bourdieu 1994).

In any case, just for that segment of people for whom religion constitutes a primordial experience in their life, it can be expected that such an experience attains a central position in the human mind, where, despite its complexity and possible differentiation into specialized cognitive domains, it could assume - consciously or less consciously - a role similar to Fodor's looked for "central processor", something missed when the mind is to be explained just through a psycho-evolutionary theory (Fodor 1983, 2000; Donald 1991, 54 f.; Carruthers and Chamberlain 2000, p. 27).

Obviously, this seems a very hypothetical and unproven view of religious meaning, paying perhaps too much attention to its possible performances among a rather limited sample of people. Just as a hypothesis, it would complement the current theories on the derived and epiphenomenal character of religious beliefs. To be sure, some derived character can still be preserved, at least from the genetic point of view, i.e. when the origins and possible development of the religious mind are exposed. But things seem to change radically when the current situation of religious committed people is examined. In these cases, a different pattern emerges, in which religion climbs to the highest place in the mind and assumes the control, becoming 
a kind of "selector of selections". The connection between religion and meaning is established in the way religion - or an alternative instance in its place - provides the grounds for the last selections, or the fundamental and most lasting decisions. Obviously, this position assumes a more decisive influence for the conscious mind, and relativizes the extent of survival and reproductive pressures, which could be even displaced from the central stage, in the name of a new and stronger "provider of meaning", assumed as a "big selector". The last claim does not diminish the reach and weight of biological influence; it just places a different anthropological instance into play, creating an opening for a new sort of "game" with more factors involved.

\subsection{Religious meaning between mind and culture}

A third approach to the likely relationship between religion and meaning resorts to theories that place the latter in the interface between the single mind and the cultural background. Bradd Shore offers useful developments in that perspective (Shore 1996). In his own words: "Meaning could be understood only as an ongoing process, an active construction by people, with the help of cultural resources" (7). The construction of meaning - in many cases - can be better understood as a process bridging culture and mind, a process which takes place through learning. A broad range of models or patterns are available in the cultural repertoire. The individuals insert their new experiences into these models to learn their meaning, shared in a social environment. For Shore meaning construction is a dynamic clearly distinct from information processing, and governed by a diverse logic; both characterize different ways to represent and understand the human mind; the first is more analogical in its functioning, the second - information processing - is more analytic.

Memory is important in that process of meaning construction, which may be explained as "a kind of remembering” (326), but one of a collective kind. In that process new events are linked to available memories and fitted into patterns; partial information is gathered into schemas able to integrate 
them in a whole; these schemas are broadly shared. The mechanism proposed is one of "pattern recognition" (338). "Meaning construction involves the apprehension of novel experience as a kind of memory, through the active mapping of new experiences onto ready-made models" (339). In this process the individual mind is perceived in a constant interplay with cultural available models; however, between them subsists a gap "which guarantees the ongoing regeneration of conventions through practice just as it makes possible intersubjective meaning" (371).

All this theory, broadly shared by further developments of the "distributed mind", and the "externalist" understanding of cognitive processes, is relevant for a different consideration on the way in which religion may be related to "meaning construction". One clue is provided by the usually condition of religion as a corpus of available schemas for individual use and application. Taking the religious mind as a no-exceptional case of "meaning-construction", it can be assumed that this process involves an on-going dealing between the individual experiences and perceptions and the available models, where, once more, a kind of "pattern recognition" and analogic dynamism is at work to shed light into a specific kind of experiences. This process is obviously open, even in strict religious forms, as the individual mind ever disposes of some margin in its application, there is a considerable pluralism of choices - included in an organic religious tradition. Furthermore, the difference or "gap" between the single mind and the religious standardized models contributes to recreate them and explains the evolution of current patterns often observed in religious history. The alluded "gap" or "breaking”, this lack of complete adjustment, allows for a more creative assumption and explains the inevitable doubts and struggles frequently associated with religious meaning construction.

Meaning in this case reflects a mind's operation looking for order, a model representing how the mind works to gain clarity and arrange experiences and perceptions in such a way that allows for the most convenient decisions. This is not just a computational form of information processing, but an analogical process of interaction with social available patterns. 
In any case, the applied schema simply explains how religious meaning construction may be seen as a particular species among the broad genus of "meaning construction". Is there any other specific trait that can be illuminated from this perspective? Perhaps the theory at hand applied to religion uncovers a kind of "extreme case" of "meaning construction", in the sense that what is at stake concerns issues which require the broadest available schema, a "big whole", and including issues of origin and finality, harder to deal from an isolated mind, and claiming for bigger social enforcements and support, traditionally furnished by myths and rituals, often of communitarian nature.

There are surely other aspects involved in the issue of religion and meaning: the role played by emotions should not be dismissed; the codification through symbols and its ritual transmission is an essential part of the story, and then the role played by the formation of "habitus" or forms of "spiritual capital" as well. Furthermore, the studies by Crystal Park on religion and meaning, related to "situational meaning" and the dynamics that allow for coping with stressful situations; and Roy Paloutzian and his program to study religions as "meaning systems" deserve a specific treatment (Park 2013; Paloutzian 2017). But all these aspects require more space and deeper reflection.

\section{Looking for empirical strategies in the study of religion, culture and meaning}

The reviewed theories can awake a sense of speculation of little use for a more scientific standard in the study of religion. Apart from their hypothetic heuristic power, an additional empirical approach is required if a more credible scientific position is sought. Probably there are several ways to better clarify the complex relationship between religion and meaning construction, and to obtain evidence in order to verify the proposed theories.

A first step could point to better clarify how much religious beliefs and the intensity of religious experience is related to indicators revealing levels of "meaning of life". The quoted review of McCullough and Willoughby 
provides useful elements to design and undertake such research. The harder side is perhaps to establish the indicators revealing "meaning of life". What could be taken in consideration? Perhaps some suggestions are at hand: levels of personal satisfaction; dimensions of life where the individual feels more realized; hope for the future; certainty in the life; ability to cope with situations of distress; the quality of familiar and social relationships; or perhaps the direct question: "Could you say that your life has meaning and purpose? Standardized questionnaires and scales are already available, gathering as many as possible items related to perceptions of meaning - in positive and negative terms - allowing, after a significative amount of data is collected, to better describe the situation in the real life in broad samples. This could at the same time test the meaning-construction strategies of the less religious people, and compare with the strategies present on those who resort to religious means. This is an open research field after several studies are trying to understand "what believe those who do not believe in religious terms", or which values and sources of meaning they find and hold to deal with many life aspects (Lee 2015; Zuckerman 2016).

A priory, the equation relating religious faith with certainty and purpose is not so clear and well defined; indeed, for a good deal of believers, faith has been a cause of struggle, doubt, anxiety and even darkness and meaninglessness. Perhaps this is the case just for a minority of believers, which can be placed mostly in the mystical tradition, but nevertheless we should be aware about the complexity of this relatedness. The last attempt to deal with that enigmatic relationship is offered by the quoted book by Routledge, as he shows - after analyzing a considerable amount of experimental data - how any attempt to project meaning in life has to resort to some self-transcending instance (2018).

A second empirical strategy could resort to a more qualitative method, interviewing a representative sample of people, or organizing focus groups, to ask them, rather through a narrative approach, to describe their own experience of meaning or lack of it, to try to gather a sufficient amount of information that could be analyzed and reveal clues about the religious meaning construction. The questions that would guide the interviewer could 
be modeled according to the three adduced models, or other alternatives, for example to ascertain whether or in which measure religious meaning is rather residual or a central element and in which cases or religious experiences it works; or how much it appears as related to individual or to shared views, usually learned in early socialization process.

There are surely more ways to empirically test the proposed models. It is important that in any case the scientific research on religion can check the evidence of its proposed theories, instead of being satisfied with thesis inspired in broad programs, or resulting from applying general models without further test.

\section{Concluding remarks}

These pages have tried to expose an alternative approach to the scientific study of religion that resorts to available developments and frameworks, which can exhibit a great level of heuristic ability. In this way, the new scientific approach to religion can be expanded and enriched to gain new insights, especially when we become more aware than only a multi-level and multi-disciplinary treatment of religion can make justice to a so complex and polyedric reality. Since meaning construction and meaning-in-life are topics that draw greater attention in psychology, anthropology and social sciences, it can be stated confidently that such a research program deserves to be pursued and to assume a central role in the new scientific study of religion.

\section{References}

Atran, Scott. 2002. In Gods We Trust. New York, Oxford: Oxford University Press. Baumeister, Roy F. 1991. Meanings of life. New York: Guilford.

Bellah, Robert. 2011. Religion in Human Evolution: From the Palaeolithic to the Axial Age, Cambridge, MA: Belknap Press. ,

Berger, Peter L. 1980. The Heretical Imperative: Contemporary Possibilities of Religious Affirmation, New York: Doubleday.

Bourdieu, Pierre. 1994. Raisons pratiques. Sur la théorie de l'action. Paris: Seuil. 
Boyer, Pascal. 2001. Religion Explained: The Evolutionary Origins of Religious Thought. New York: Basic Books.

Carruthers, Peter and Andrew Chamberlain. 2000. Evolution and the Human Mind: Modularity, Language and Meta-Cognition. Cambridge-New York: Cambridge University Press.

De Caro, Mario and David Macarthur (eds.). 2004. Naturalism in Question. Cambridge MA - London U.K.: Harvard University Press.

Donald, Merlin. 1991. Origins of the Modern Mind. Harvard, MA-London U.K.: Harvard University Press.

Donald, Merlin. 2001. A Mind so Rare: The Evolution of Human Consciousness. New York-London: W.W. Norton \& Co.

Eagleton, Terry. 2007. The Meaning of Life. Oxford - New York: Oxford University Press. Elias, Norbert. 1994. The Civilizing Process. Oxford: Basil Blackwell.

Flanagan, Owen, The Really Hard Problem: Meaning in a Material World, Cambridge, MA, London U.K.: MIT Press, 2008.

Fodor, Jerry 1983. The Modularity of Mind. Cambridge, MA.: MIT Press.

Fodor, Jerry. 2000. The Mind Doesn't Work That Way: The Scope and Limits of Computational Psychology. Cambridge, MA.: MIT Press.

Gasser, Georg (ed.). 2007. How Successful is Naturalism? Frankfurt a.M.-Paris: Ontos Verlag.

Geertz, Clifford. 1973. Religion as a cultural system. In: The interpretation of cultures: selected essays, New York: Basic Books, 87-125.

Hicks, Joshua A. and Clay Routledge (Eds.). 2013. The Experience of Meaning in Life: Classical Perspectives, Emerging Themes, and Controversies. Dordrecht, Heidelberg and New York: Springer.

Horst, Steven. 2007. Beyond Reduction: Philosophy of Mind and Post-Reductionist Philosophy of Science. Oxford-New York: Oxford University Press.

Horst, Steven. 2016. Cognitive Pluralism. Cambridge, MA: MIT Press.

Horwich, Paul. 1998. Meaning. Oxford-New York: Oxford University Press.

Lee, Lois. 2015. Recognizing the non-religious. Oxford-New York: Oxford University Press.

Luhmann, Niklas. 1977. Funktion der Religion. Frankfurt a.M.: Suhrkamp.

Luhmann, Niklas. 1985. "Society, Meaning, Religion- Based on Self-Reference." Sociological Analysis 46: 5-20.

Luhmann, Niklas. 1989. Gesellschaftsstruktur und Semantik: Studien zur Wissenssoziologie del modernen Gesellschaft, 3. Frankfurt a.M.: Suhrkamp.

Luhmann, Niklas. 2000. Die Religion der Gesellschaft. Frankfurt a.M.: Suhrkamp. 
McCullough, Michel E. and Brian L.B. Willoughby. 2009. "Religion, Self-Regulation, and Self-Control: Associations, Explanations, and Implications.” Psychological Bulletin 135-1: 69-93.

Neuman, Yair. 2006. “A Theory of Meaning.” Information Sciences 176: 1435-1449.

Newton, Taylor and Daniel McIntosh. 2013. "Unique Contributions of Religion to Meaning." In The Experience of Meaning in Life: Classical Perspectives, Emerging Themes, and Controversies, edited by Hicks, Joshua A. and Clay Routledge, 257-270. Dordrecht, Heidelberg and New York: Springer.

North, Douglass. 2005. Understanding the Process of Economic Change. Princeton, N.J.: Princeton University Press.

Paloutzian, Raymond F. 2017. "Psychology of Religion in the World." Pistis Praxis 9-1:15-30.

Park, Crystal L. 2010. “Making Sense of the Meaning Literature: An Integrative Review of Meaning Making and Its Effects on Adjustment to Stressful Life Events.” Psychological Bulletin 136: 257-301.

Park, Crystal L. 2013. “The Meaning Making Model: A framework for understanding meaning, spirituality and stress-related growth in health psychology.” The European Health Psychologist 15-2: 40-47.

Routledge, Clay. 2018. Supernatural: Death, Meaning, and the Power of the Invisible World. New York: Oxford University Press.

Shore, Bradd. 1996. Culture in Mind: Cognition, Culture, and the Problem of Meaning. Oxford-New York: Oxford University Press.

Spaemann, Robert. 1994. „Funktionale Religionsbegründung und Religion“ in Philosophische Essays. Ditzingen: Reclam.

Steiner, George. 1989. Real Presences. Chicago: University of Chicago Press.

Zuckerman, Phil, Luke W. Galen, Frank L. Pasquale. 2016. The Nonreligious: Understanding secular people \& societies. Oxford-New York: Oxford University Press. 